\title{
Recurrent simple bone cyst of the mandibular condyle: a case report
}

\author{
Kyoung-A Kim, Kwang-Joon Koh \\ Department of Oral and Maxillofacial Radiology, School of Dentistry, and Institute of Oral Bio Science, Chonbuk National University, \\ Jeonju, Korea
}

ABSTRACT

Cysts of the mandibular condyle are rare and can be difficult to diagnose and treat. Clinically, a simple bone cyst is asymptomatic and often discovered incidentally on routine radiographic examination. This report shows an atypical simple bone cyst occurring in the mandibular condyle showing recurrence after surgical curettage. Radiologically, this lesion involving the mandibular condyle should be distinguished from other similar lesions such as a chondroma, a central giant cell granuloma, and an aneurysmal bone cyst. Radiographic assessment was useful for forecasting the prognosis of a simple bone cyst. Possible reasons for the recurrence were discussed radiographically. (Imaging Sci Dent 2013; 43 : 49-53)

KEY WORDS: Bone Cysts; Mandibular Condyle; Radiography, Panoramic; Cone-Beam Computed Tomography

A simple bone cyst $^{1}$ is also known as a solitary bone cyst, ${ }^{2}$ a traumatic bone cyst, ${ }^{3}$ a hemorrhagic bone cyst, ${ }^{4}$ an extravasation cyst, ${ }^{5}$ an idiopathic bone cavity, ${ }^{6}$ and a progressive bone cyst or cavity. ${ }^{7}$ These terms reflect the uncertain etiologies of simple bone cysts, although it has been supposed that simple bone cysts might be associated with traumatically-induced hematoma within the intramedullary portion of the bone. ${ }^{2,8}$

Simple bone cysts are commonly located in the mandibular body of the jaw. ${ }^{3}$ However, several atypical lesions localized in the mandibular condyle, ramus, or both have been reported. ${ }^{8-14}$ An early diagnosis of a simple bone cyst can be made by history taking, physical examination, and radiographic examination. It should be radiologically distinguished from other lesions, such as a central giant cell granuloma ${ }^{15}$ and an aneurysmal bone cyst, ${ }^{16,17}$ due to its similar clinical and radiologic characteristics.

Simple bone cysts of the jaws are treated primarily by surgical exploration ${ }^{9}$ even though previous studies ${ }^{18-20}$ have reported various treatments and prognosis, and sev-

Received May 29, 2012; Revised July 20, 2012; Accepted July 29, 2012

Correspondence to : Prof. Kyoung-A Kim

Department of Oral and Maxillofacial Radiology, School of Dentistry, 634-18 Keumam-dong, Dukjin-gu, Jeonju 561-712, Korea

Tel) 82-63-250-2220, Fax) 82-63-250-2081, E-mail) beam@jbnu.ac.kr eral authors have reported recurrences of these cysts. ${ }^{12,21,22}$ Radiographic assessment is useful for predicting the prognosis of simple bone cysts. The radiographic features of the scalloped margin, absent lamina dura, nodular bone expansion, and/or multiple cavities may suggest an increased risk for recurrence. ${ }^{21}$

This report described an atypical case of a simple bone cyst involving the mandibular condyle, which recurred after surgery.

\section{Case Report}

A healthy 16-year-old boy was referred for the evaluation and management of an asymptomatic radiolucency of the left mandibular condyle that was noted on a routine panoramic radiograph. A history of no trauma was elicited, and the familial and medical histories were not contributory. Physical examination revealed a slight mandibular laterognathism, normal mandibular excursions, and a painless range of motion in spite of class III malocclusion. The occlusion was unstable, and clicking sounds were detected at the right temporomandibular joint (TMJ) during mouth opening. No cervical lymphadenopathy was detected, and no intraoral swelling or deformity was visible.

A panoramic radiograph showed a well-defined multi-

Copyright (c) 2013 by Korean Academy of Oral and Maxillofacial Radiology

This is an Open Access article distributed under the terms of the Creative Commons Attribution Non-Commercial License (http://creativecommons.org/licenses/by-nc/3.0) which permits unrestricted non-commercial use, distribution, and reproduction in any medium, provided the original work is properly cited. Imaging Science in Dentistry • pISSN 2233-7822 eISSN 2233-7830 

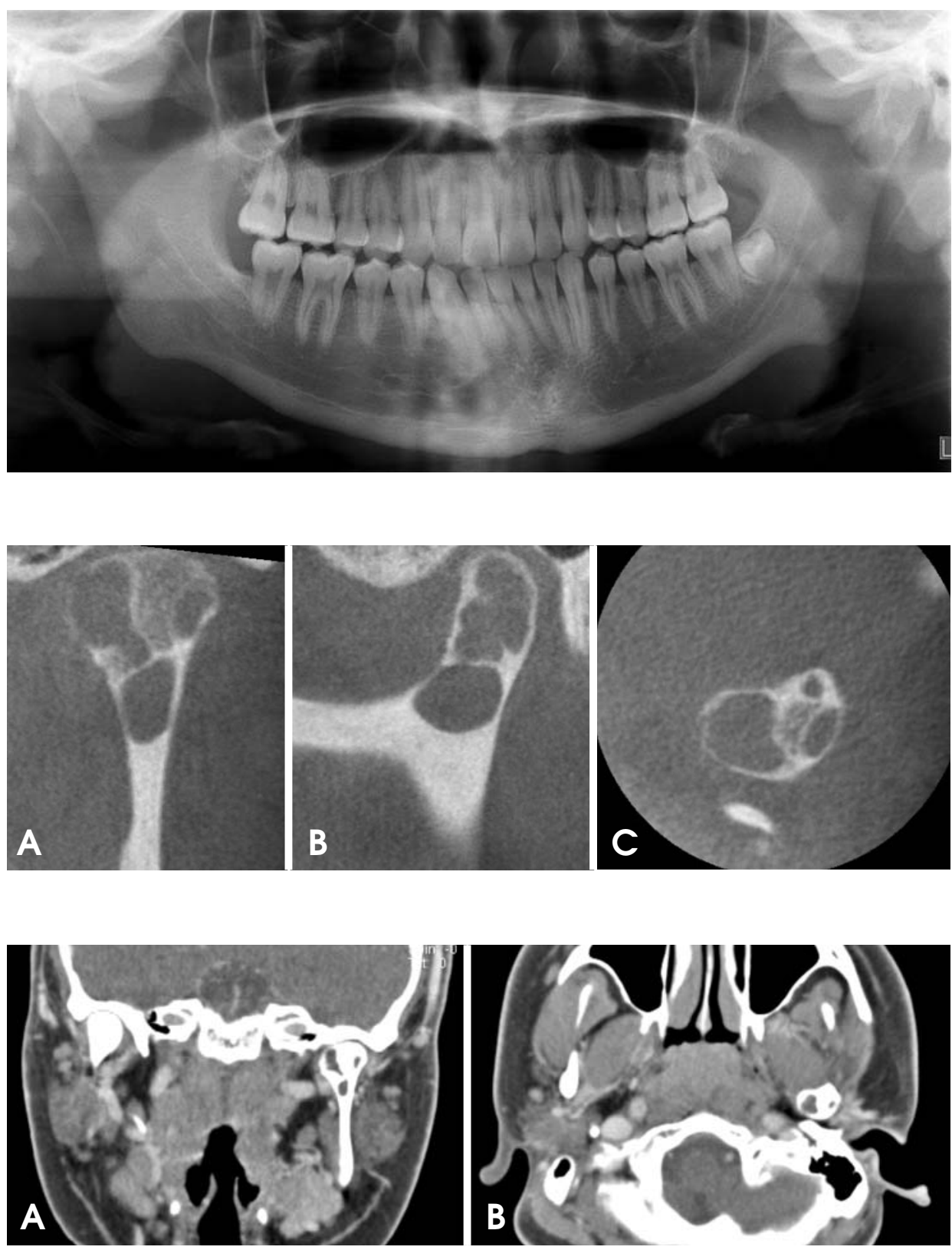

Fig. 1. Panoramic radiograph shows well-defined multilocular radiolucency in the left mandibular condyle.

Fig. 2. Coronal (A), sagittal(B), and axial (C) CBCT images show an amorphous multilocular lytic lesion and a scalloped cortical border in some parts.

Fig. 3. Coronal (A) and axial (B) enhanced CT scans show a nonenhanced multilocular lesion in the left mandibular condyle. locular radiolucent lesion located in the left mandibular condyle. The mandible was deviated to the left side due to hypertrophy of the right mandible. Multiple lower anterior teeth were tilted to compensate for the hemimandibular hypertrophy, and the occlusal relationship was poor on maximum occlusion (Fig. 1). The cone-beam computed tomography (CBCT) scans showed that the lesion was an amorphous multilocular lytic lesion that had a thinned, well-defined, and scalloped cortical border in some parts (Fig. 2). The enhanced computed tomography (CT) scans revealed a non-enhanced multilocular lesion, which had CT values from -10 to 8 Hounsfield units (HU) (Fig. 3). Magnetic resonance imaging (MRI) showed homogeneous intermediate signal intensity (SI) on T1-weighted images and homogeneous high SI on T2-weighted images, with a clear border in both images. The articular disc of the TMJ was located in a normal position (Fig. 4). A tentative radiographic diagnosis of the simple bone cysts was made, and central giant cell granulomas and aneurysmal bone cysts were included in the differential diagnosis of the lesion.

Surgery was performed under general anesthesia through an incision of the left posterior vestibule. The half of the mandibular ramus containing the mandibular condyle was rejected and eviscerated. The condylar defect with a partially thin cortical plate was revealed. The cortical plate was removed in parts, and the internal walls of the cavities 

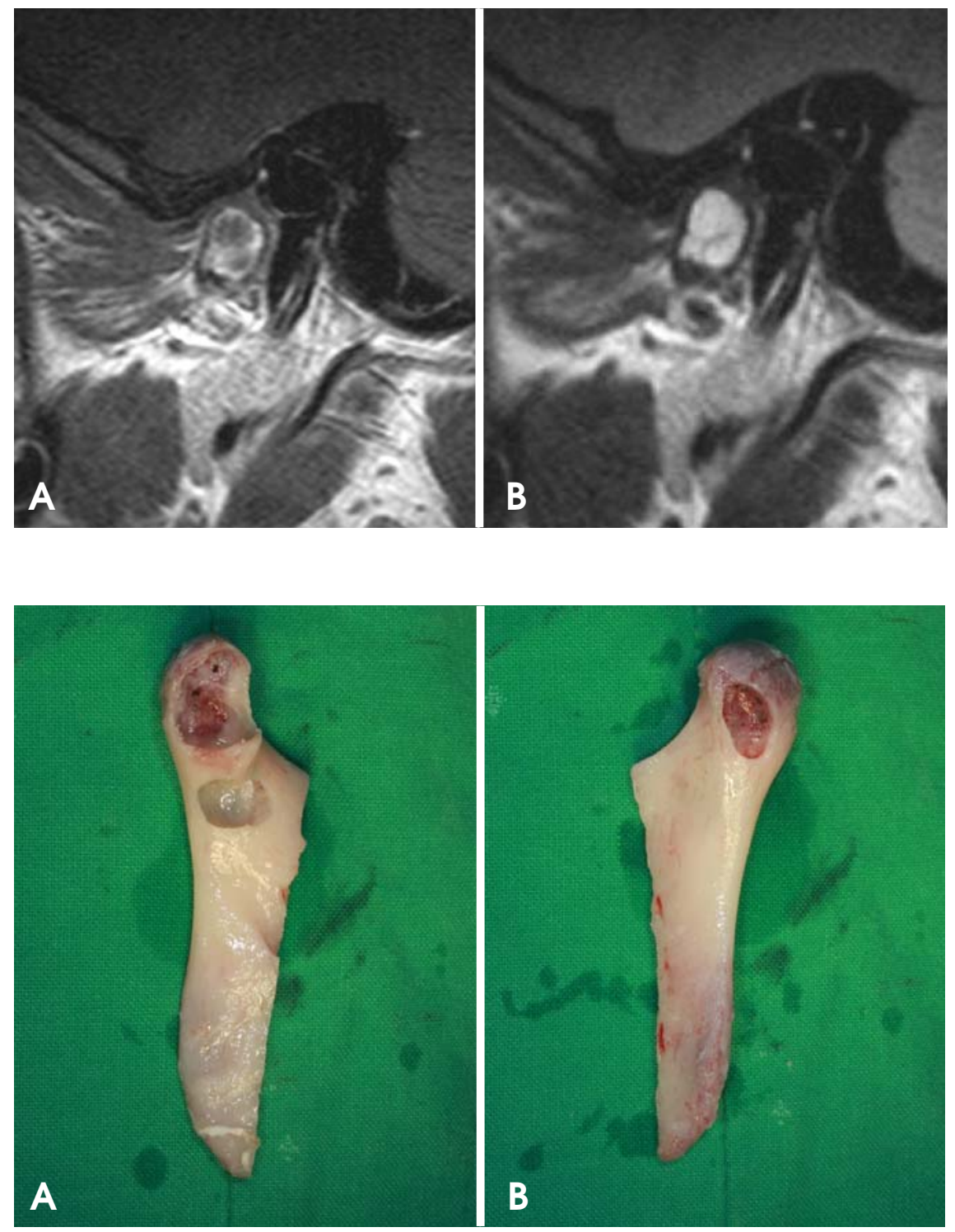

Fig. 4. MRI shows homogeneous intermediate SI on the T1-weighted image (A) and homogeneous high SI on the T2-weighted image (B)

Fig. 5. The eviscerated and curetted mandibular condyle. A. Medial pole. B. Lateral pole. were lightly curetted (Fig. 5). Small amounts of tissue obtained from the defect for microscopic examination were negative for epithelium. The eviscerated bone segment was repositioned to its original state and fixed with miniplates.

Microscopic examination of the specimen showed a cystic lesion without an epithelial lining, which was surrounded by dense fibrous connective tissue. Osteoid bone was also seen in the connective tissue indicating reactive bone formation. These features were consistent with those of simple bone cysts (Fig. 6).

A 14-month postoperative radiographic follow-up showed a recurred lesion at the left mandibular condyle. The lesion had recurred on the previously scalloped part. It showed radiolucency with an expanded, scalloped cortical plate on the CBCT images. A second surgical excision

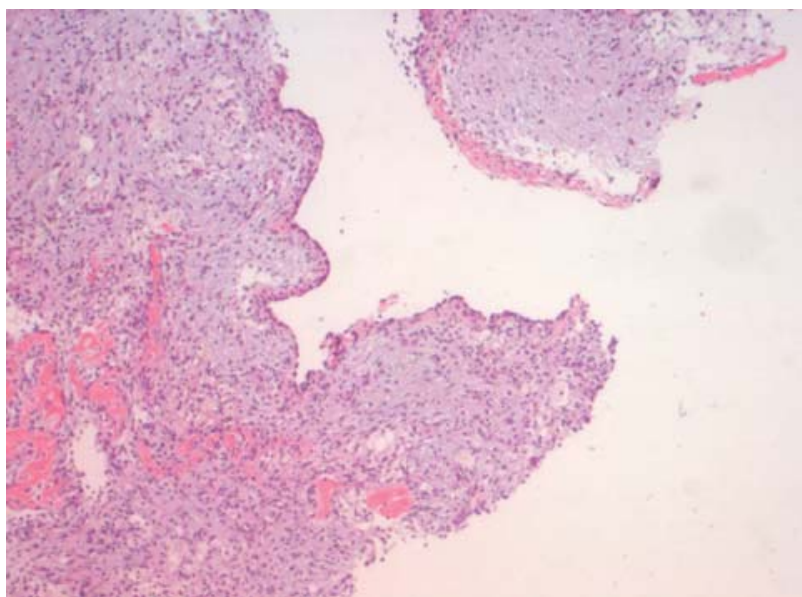

Fig. 6. Microscopic examination shows a cyst without an epithelial lining, which is surrounded by dense fibrous connective tissue and reactive bone $(H \& E$ stain, $\times 100)$. 
was performed using the preauricular approach. The microscopic features were similar to those of the initial biopsy specimen.

The 6-month postoperative recovery was unsatisfactory even though there was no sign of recurrence. The patient was treated for hemihypesthesia of the left lower face due to a left facial nerve injury followed by a pre-auricular surgical approach.

\section{Discussion}

The etiology of simple bone cysts remains unclear, but the most commonly suggested etiology is a traumatically induced hemorrhage. A subsequent failure of clotting leaves an empty cavity within the bone. ${ }^{2,8}$ The pathogenesis in this case is unclear because there was no history of trauma to the maxillofacial region. ${ }^{9,13,14}$ However, it should not be ruled out that chronic occlusal trauma may have had an influence on the pathogenesis of a simple bone cyst. Ogasawara et $\mathrm{al}^{25}$ has suggested that occlusal trauma might be a contributing factor in simple bone cysts. The case reported here had slight mandibular laterognathism and unstable occlusion; therefore, chronic occlusal trauma was considered to be the etiology of the lesion. On the other hand, the absence of trauma ${ }^{9,13,14}$ and the untypical site, such as the posterior mandible, which is not prone to trauma, ${ }^{2,23}$ are the factors for distrusting the traumatichemorrhagic theory. The other theory is that a simple bone cyst might be developmental in origin. ${ }^{2,8}$ According to this theory, the mesenchymal tissue becomes immature synovial tissue instead of developing into bone or cartilage. The simple bone cyst originates as multiple bursa-like synovial cavities, which coalesce to form a larger connective tissue-lined defect. This could account for its shape and size, which becomes independent of internal pressures, its non-displacement of teeth and neurovascular bundles, and its irregular outline. Similarly, one would expect the cyst to disappear with age and hence the lower incidence in the older patients. ${ }^{2}$

Most simple bone cysts are asymptomatic. ${ }^{1,3,13,14}$ However, in the 10 reported cases of simple bone cysts of the mandibular condyle, including our case, the cysts caused several kinds of symptoms including one case with painless swelling, 3 with a clicking sound in the TMJs, 1 with swelling and a clicking sound in the TMJ, 3 with pain immediately after trauma, and 2 with no symptoms. ${ }^{8,10-14,24,25}$ The higher presence of the clinical symptoms on the simple bone cyst of the mandibular condyle might be due to the location of the lesions. The clicking sound and imme- diate pain after trauma might be associated with TMJ dysfunction and a pathologic fracture of thinned bone, respectively, but not the cystic process in the condyle.

Commonly, the radiographic appearance of a simple bone cyst is a radiolucent lesion with an irregular or scalloped but well-defined margin. The size is variable, and a fine sclerotic margin is sometimes seen. When the radiolucency affects the interdental bone spaces, the lesion appears lobular or scalloped. ${ }^{1,3,26,27}$ However, simple bone cysts sometimes show multilocular and/or partly diffused borders. In our case, a panoramic radiograph and CBCT scans showed a well-defined multilocular radiolucency of the condyle with a thin and scalloped cortical border in the medial pole of the condyle. The enhanced CT scans revealed that the non-enhanced lesion ranged from -10 to $8 \mathrm{HU}$, indicating fluid in the cavity. Suei et $\mathrm{al}^{28}$ evaluated the radiographs of simple bone cysts to determine if liquid and/or air were present in the bone cavity. Their study revealed that there was no air-liquid level on the panoramic radiographs nor any low density areas on the CT images of the cavity, and the $\mathrm{CT}$ values in the cavity ranged from -50 to $100 \mathrm{HU}$, which indicated the presence of liquid. These results were different with the surgical findings of the presence of air in the cavity in some cases. They concluded that the air entered the cavity in the place of the fluid that was aspirated or that leaked through the cortical bone split during the surgical procedure. In our case, MRI showed homogeneous intermediate SI on the T1-weighted images and homogeneous high SI on the T2-weighted images with a clear border indicating a fluid-filled lesion. This finding was consistent with other previous reports. ${ }^{11,25,29}$

Radiologically, a simple bone cyst involving the mandibular condyle should be distinguished from other similar lesions such as chondroma, osteoblastoma, eosinophilic granuloma, central giant cell granuloma, and aneurysmal bone cyst. Enhanced CT and MRI are helpful for differentiating these lesions. Matsuzaki et $\mathrm{al}^{29}$ emphasized the usefulness of dynamic MRI for distinguishing simple bone cysts from other cysts or tumors. According to their reports, the simple bone cysts were enhanced from the margin to the inner part on the dynamic MRI, indicating a gradual exudation of the contrast agent from the surrounding medullae to the inner part. They also reported that these phenomena were not observed on the dynamic MRI of the other true cysts with epithelial lining.

In our case, a simple bone cyst recurred in spite of a thorough surgical curettage of the lesions. The lesion in this case was radiographically bilocular and had a scalloped margin with a thin cortical outline on the medial 
pole of the condyle. Suei et $\mathrm{al}^{21}$ suggested a relationship between the radiographic features and prognosis of a simple bone cyst. They proposed that the radiographic features showing a high recurrence rate of the lesion were a scalloped margin, multilocular appearance, absence of lamina dura, root resorption, nodular bone expansion, and/or internal radiopaque masses. A careful radiographic analysis of simple bone cysts and follow-up to complete radiographic resolution are important for preventing the possible recurrence or persistence of the lesion.

\section{References}

1. Forssell K, Forssell H, Happonen RP, Neva M. Simple bone cyst. Review of the literature and analysis of 23 cases. Int $\mathrm{J}$ Oral Maxillofac Surg 1988; $17: 21-4$.

2. Hosseini M. Two atypical solitary bone cysts. Br J Oral Surg $1979 ; 16: 262-9$.

3. Cortell-Ballester I, Figueiredo R, Berini-Aytés L, Gay-Escoda C. Traumatic bone cyst: a retrospective study of 21 cases. Med Oral Patol Oral Cir Bucal 2009; 14 : E239-43.

4. Khosla VM. Hemorrhagic bone cyst of mandible. Report of a case. Oral Surg Oral Med Oral Pathol 1970; 30 : 723-9.

5. Peters RA, Wussow GC. Extravasation cyst of the maxilla. Report of a case. Oral Surg Oral Med Oral Pathol 1968; 26 : $742-5$.

6. Velez I, Siegel MA, Mintz SM, Rolle R. The relationship between idiopathic bone cavity and orthodontic tooth movement: analysis of 44 cases. Dentomaxillofac Radiol 2010; 39 : 1626.

7. Robinson M, Canter S, Shuken R. Multiple progressive bone cysts of the mandible and maxilla. Oral Surg Oral Med Oral Pathol 1967; 23 : 483-6.

8. Persson G. An atypical solitary bone cyst. J Oral Maxillofac Surg 1985; $43:$ : 905-7.

9. Gilman RH, Dingman RO. A solitary bone cyst of the mandibular condyle. Plast Reconstr Surg 1982; 70 : 610-4.

10. Shigematsu H, Fujita K, Watanabe K. Atypical simple bone cyst of the mandible. A case report. Int J Oral Maxillofac Surg 1994; 23 : 298-9.

11. Tanaka H, Westesson P, Emmings FG, Marashi AH. Simple bone cyst of the mandibular condyle: report of a case. J Oral Maxillofac Surg 1996; 54 : 1454-8.

12. Kuttenberger JJ, Farmand M, Stöss H. Recurrence of a solitary bone cyst of the mandibular condyle in a bone graft. A case report. Oral Surg Oral Med Oral Pathol 1992; 74 : 550-6.

13. Rubin MM, Murphy FJ. Simple bone cyst of the mandibular condyle. J Oral Maxillofac Surg 1989; 47 : 1096-8.

14. Magliocca KR, Edwards SP, Helman JI. Traumatic bone cyst of the condylar region: report of 2 cases. J Oral Maxillofac Surg 2007; $65:$ 1247-50.

15. Jadu FM, Pharoah MJ, Lee L, Baker GI, Allidina A. Central giant cell granuloma of the mandibular condyle: a case report and review of the literature. Dentomaxillofac Radiol 2011; 40 : 60-4.

16. Yu JJ, Park JH, Kang JH, Kim GT, Choi YS, Hwang EH. Aneurysmal bone cyst of the mandibular condyle with condylar neck fracture. Korean J Oral Maxillofac Radiol 2009; 39 : 205-8.

17. Motamedi MH. Destructive aneurismal bone cyst of the mandibular condyle: report of a case and review of the literature. J Oral Maxillofac Surg 2002; 60 : 1357-61.

18. Damante JH, Da S Guerra EN, Ferreira Jr O. Spontaneous resolution of simple bone cysts. Dentomaxillofac Radiol 2002; $31: 182-6$.

19. Sapp JP, Stark ML. Self-healing traumatic bone cysts. Oral Surg Oral Med Oral Pathol 1990; 69 : 597-602.

20. Chapman PJ, Romaniuk K. Traumatic bone cyst of the mandible: regression following aspiration. Int J Oral Surg 1985; 14 : 290-4.

21. Suei Y, Taguchi A, Nagasaki T, Tanimoto K. Radiographic findings and prognosis of simple bone cysts of the jaws. Dentomaxillofac Radiol 2010; 39 : 65-71.

22. Feinberg SE, Finkelstein MW, Page HL, Dembo JB. Recurrent "traumatic" bone cysts of the mandible. Oral Surg Oral Med Oral Pathol 1984; 57 : 418-22.

23. Mathew R, Omami G, Gianoli D, Lurie A. Unusual cone-beam computerized tomography presentation of traumatic (simple) bone cyst: case report and radiographic analysis. Oral Surg Oral Med Oral Pathol Oral Radiol 2012; 113 : 410-3.

24. Telfer MR, Jones GM, Pell GM, Eveson JW. Primary bone cyst of the mandibular condyle. Br J Oral Maxillofac Surg 1990; $28: 340-3$.

25. Ogasawara T, Kitagawa Y, Ogawa T, Yamada T, Yamamoto S, Hayashi K. Simple bone cyst of the mandibular condyle with severe osteoarthritis: report of a case. J Oral Pathol Med 1999; $28: 377-80$.

26. Choi SC, Lee SS, Lee GI. Radiologic study of the traumatic bone cysts. J Korean Acad Oral Maxillofac Radiol 1994; 24 : 7-21.

27. Oh KR, Park WK, Ko JK, Kim YJ. A study of the traumatic bone cyst. J Korean Acad Oral Maxillofac Radiol 1997; 27 : 145-60.

28. Suei Y, Tanimoto K, Wada T. Simple bone cyst. Evaluation of contents with conventional radiography and computed tomography. Oral Surg Oral Med Oral Pathol 1994; 77 : 296301.

29. Matsuzaki H, Asaumi J, Yanagi Y, Konouchi H, Honda Y, Hisatomi M, et al. MR imaging in the assessment of a solitary bone cyst. Eur J Radiol Extra 2003; 45 : 37-42. 